\title{
DETECÇÃO E CORREÇÃO DE OUTLIERS EM CURVAS DE POTÊNCIA UTILIZANDO TÉCNICA HÍBRIDA DE INTELIGÊNCIA ARTIFICIAL
}

\author{
Pedro H. M. de Andrade*, Juan M. M. Villanueva ${ }^{\dagger}$ \\ * Departamento de Engenharia Elétrica, UFPB, João Pessoa/Brasil \\ Cidade Universitária, João Pessoa-PB, CEP:58.051-900 \\ †Departamento de Engenharia Elétrica, UFPB, João Pessoa/Brasil \\ Cidade Universitária, João Pessoa-PB, CEP:58.051-900
}

Emails: pedro.andrade@cear.ufpb.br, jmauricio@cear.ufpb.br

\begin{abstract}
The distribution substations power curves are often affected by outliers: very discrepant measurements of the curve standard behavior. If the presence of outliers is very large, the internal studies and analysis of the power utilities developed from the history of the data collected may be compromised. In order to detect and correct atypical data, a complementary module for the Supervisory System was developed. In the previous work of the authors, two techniques were developed based on artificial intelligence: fuzzy logic and artificial neural networks. In this work is presented a hybrid technique that uses the best performances of the previous ones. Also developed in this paper, is an outlier detection method based on the standard behavior of the curve and the distribution of the collected samples. The performances of the techniques are compared using real data from a substation over 6 years.
\end{abstract}

Keywords- Outliers detection, correction, power curves, artificial intelligence, fuzzy logic, neural networks, hybrid technique.

\begin{abstract}
Resumo- As curvas de potência das subestações de distribuição são frequentemente afetadas por outliers, isto é, medições muito discrepantes do comportamento padrão da curva. Se a presença de outliers for muito grande, os estudos e análises internas das concessionárias desenvolvidas a partir do histórico dos dados coletados podem ser inviabilizados. Com o objetivo de detectar e corrigir os dados atípicos, foi desenvolvido um módulo complementar para o Sistema Supervisório. Em trabalho anterior dos autores, foram desenvolvidas duas técnicas baseadas em inteligência artificial: lógica fuzzy e redes neurais artificiais. Neste trabalho é apresentada uma técnica híbrida que utiliza as melhores performances das anteriores. Também foi desenvolvido neste artigo um método de deteç̧ão de outliers baseado no comportamento padrão da curva e da distribuição das amostras coletadas. Os desempenhos das técnicas são comparados utilizando dados reais de uma subestação ao longo de 6 anos.
\end{abstract}

Palavras-chave- Detecção, correção, Outliers, curvas de potência, inteligência artificial, lógica fuzzy, redes neurais, técnica híbrida.

\section{Introdução}

As redes elétricas estão evoluindo para sistemas inteligentes, conhecidas na literatura como Smart Grids, e necessitam cada vez mais de apoio ao gerenciamento da rede. O Sistema SCADA (Supervisory Control and Data Acquisition), portanto, tem papel fundamental nas novas infraestruturas dos sistemas elétricos de potência, que requerem uma comunicação integral com o centro de controle das concessionárias (Lanzrath et al., 2017).

As redes inteligentes contam com sensores, atuadores, processamento em tempo real, novas interfaces e novos protocolos de comunicação que permitem ao sistema introduzir características de auto-recuperação com capacidade de detectar, analisar e corrigir falhas na rede de forma automática (Fang et al., 2012).

As distribuidoras possuem interesse nos dados coletados pelo sistema de medição, pois através do histórico formado são desenvolvidas análises, planos de manutenção e operação, além da previsão de carga sobre as áreas de distribuição. Por exemplo, um estudo sobre o histórico dos dados pode indicar quais regiões estão crescendo mais, devendo ser dada uma maior atenção e uma me- lhor alocação de recursos (Xenias et al., 2015).

Entretanto, os dados coletados pelo Sistema SCADA podem ser afetados por falta de energia, erros de comunicação, instabilidade na medição. Essas ocorrência podem gerar valores medidos discrepantes do comportamento padrão da carga, denominados na literatura de outliers (Melo and Castro, 2014).

Então diante da importância do histórico dos dados, a qualidade e a integralidade das medições deve ser buscadas, pois para as atividades de operação, manutenção e previsão de séries temporais é importante uma integralidade mínima dos dados medidos (Ye et al., 2016).

Em (Andrade et al., 2018), os autores deste trabalho desenvolveram um módulo complementar ao Sistema SCADA para corrigir outliers em curvas de potência de subestações baseado em Inteligência Artificial, uma técnica utilizando Lógica Fuzzy e outra baseada em Redes Neurais Artificiais (RNA).

Neste trabalho, é apresentada uma nova técnica para o módulo complementar, que consegue reduzir ainda mais os erros de previsão ao particionar as medições de um dia e utilizar as melhores 


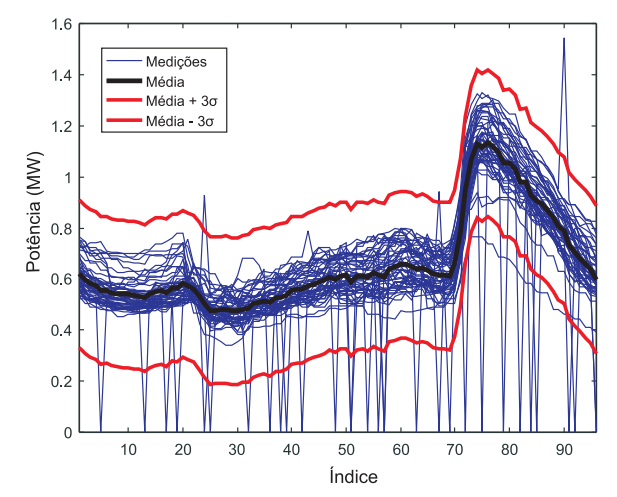

Figura 1: Curvas de todas as quartas-feiras do ano de 2010 no Alimentador 21L4 da subestação estudada.

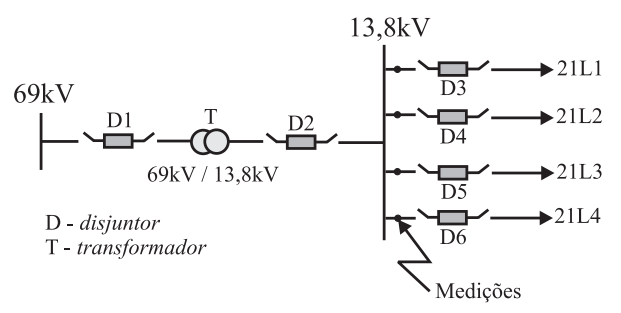

Figura 2: Modelo da Subestação estudada.

técnicas para cada faixa de horário. Neste artigo também é desenvolvida uma técnica de correção que não estava presente em (Andrade et al., 2018), baseada nas diferenças entre os valores medidos e os valores típicos de medição. E desta maneira podem ser identificados tantos os outliers do tipo "vale", de valor zero, quanto do tipo "pico". Serão apresentados os resultados da correção de outliers considerando um alimentador de uma subestação abaixadora real de $69 \mathrm{kV} / 13,8 \mathrm{kV}$, localizada no estado da Paraíba.

\section{Sistema SCADA e Outliers}

As leituras dos medidores do sistema elétrico geralmente são coletadas pelo Sistema SCADA e processadas por um estimador para filtrar o ruído e detectar erros. As medições contêm erros relacionados ao ruído, mas também dados errôneos, conhecidos na literatura como bad data, nos quais os outliers são exemplos dos dados indesejáveis (Yang et al., 2011).

Diversas metodologias para detecção e correção de outliers têm sido desenvolvidas para diversos domínios de aplicações como engenharia, economia, metereologia, dentre outros. E para cada domínio de aplicação tende a ser desenvolvido um método único de acordo com o tipo de série temporal e o tipo de outlier (Ye et al., 2016). Por exemplo, em (Valverde and Terzija., 2011) é utilizada uma técnica de estimação de estados que é eficiente, desde que o modelo da série temporal seja preciso e que obedeça algumas propriedades estatísticas (Zhang et al., 2011).

Pode-se observar a presença dos outliers nas curvas de demanda pela Figura 1 que ilustra todas as quartas-feiras do ano de 2010 no Alimentador 21L4. As medições são realizadas a cada 15 minutos, totalizando 96 medições por dia. Portanto, o eixo das abscissas refere-se ao índice das amostras coletadas pelo SCADA. Por exemplo, o índice 1 refere-se às 00h00, o 2 refere-se às 00h15, e assim por diante, até às $23 \mathrm{~h} 45$ com índice igual a 96 . A topologia da subestação estudada é Arranjo Simples Abaixadora, como ilustrada na Figura 2. Os medidores são localizados nos troncos dos 4 alimentadores (21L1, 21L2, 21L3 e 21L4) que suprem 4 regiões próximas.

As curvas de carga possuem outliers tipo vale e, em menor frequência, do tipo pico. Contudo, não há nenhum tratamento no Sistema SCADA que identifique e corrija as medições errôneas, prejudicando o histórico dos dados. Portanto, diante desta necessidade, foi desenvolvido um módulo para complementar o SCADA da concessionária ao detectar e corrigir os outliers das curvas de potência.

\section{Módulo Desenvolvido para Tratamento dos Outliers}

O tratamento dos outliers consiste tanto na detecção dos valores atípicos como sua respectiva correção. Neste trabalho foi desenvolvido um método que detecta os outliers com base nos padrões típicos da curva. Serão considerados os outliers tipo vale ou ausência de dados, isto é, quando a medição armazenada pelo SCADA tem valor igual a zero. Assim como os outliers do tipo pico, isto é, as medições errôneas possuem uma magnitude muito superior ao padrão normal da curva.

Segundo (Charytoniuk and Chen, 2000), para as previsões de curtíssimo prazo (minutos ou horas à frente) devem ser levadas em consideração apenas as últimas amostras medidas, desconsiderando fatores como condições climáticas e características socioeconômicas da região. Portanto, o Módulo de Tratamento de Outliers proposto verifica se o novo dado medido é um valor atípico. Em caso positivo, este valor será descartado e substituído pelo valor estimado na iteração anterior. Caso não seja um outlier, o valor medido será considerado válido e adicionado ao banco de dados históricos, conforme Figura 3.

Foram desenvolvidas técnicas de correção de outliers em (Andrade et al., 2018) e elas serão comparadas neste trabalho com a nova técnica proposta: a abordagem Híbrida. Serão apresentadas a seguir o Método de Detecção e os Métodos de Correção implementados, com ênfase na abordagem Híbrida, que utiliza as melhores performances da técnica fuzzy e da técnica RNA. 


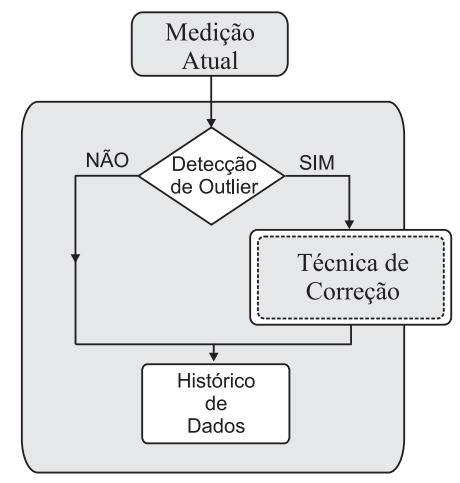

Figura 3: Fluxograma do Módulo de Tratamento de Outliers desenvolvido.

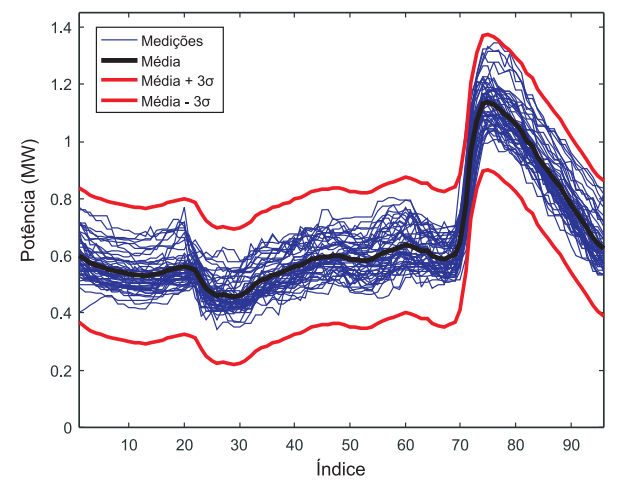

Figura 4: Distribuição das medições com indicação da média e da média mais e menos o triplo do desvio padrão.

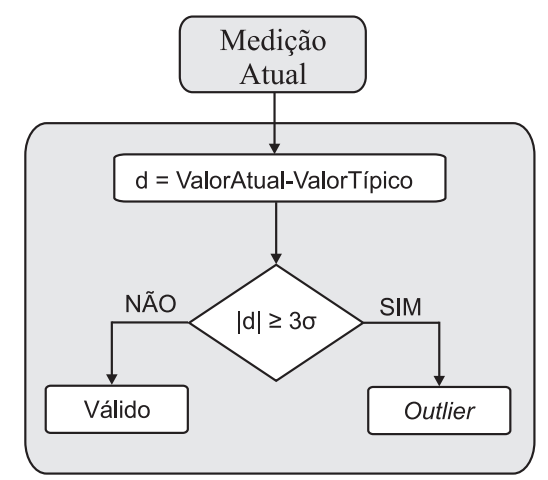

Figura 5: Método de Detecção de Outliers desenvolvido.

\subsection{Método de Detecção de Outliers}

Inicialmente, os dados do período de um ano foram separados de acordo com o dia da semana. Isto é, sendo 52 semanas durante o ano, serão extraídos os 52 dias de domingo com 96 medições para cada dia. Então para cada dia foi construída uma matriz de dimensões $96 \times 52$, isto é, 52 dias e cada dia com 96 medições. A média e o desvio padrão de cada índice foram calculados. Por exemplo, para o índice 1 , referente ao horário $00 \mathrm{~h} 00$, todos os valores dos 52 domingos foram somados e divididos por 52. Foi feito desta forma para to- dos os índices dos dias fechando com o de número 96 , referente a $23 \mathrm{~h} 45$. A curva das médias, denominada Curva Típica, foi calculada para cada dia da semana. Assim como o desvio padrão associado para o índice de cada dia.

Todas as terças do ano 2010 são ilustradas na Figura 4, em que a curva de cor preta representa a média, denominada Terça Típica. As curvas de cor azul são referentes às 52 terças do ano e as curvas em vermelho representam a média mais e menos o triplo do maior desvio padrão do dia. Considerando uma distribuição Gaussiana, 99,73\% de todas as amostras estarão dentro deste intervalo, sendo este o critério de correção adotado.

No Método de Detecção, a cada novo valor de entrada, o algoritmo identifica qual o dia da semana e qual o índice do dia, dentro do intervalo [1:96] equivalente a $00 \mathrm{~h} 00$ a $23 \mathrm{~h} 45$. Por exemplo, se o outlier ocorrer em uma Quarta-feira no índice 5 (1h00), então o valor medido será subtraído do valor de índice 5 da Quarta Típica. Se a diferença $(d)$ for maior que três vezes o desvio padrão máximo $(\sigma)$ deste ano, então o valor medido será considerado outlier, conforme Figura 5. Este método permite detectar outliers do tipo vale e do tipo pico.

\subsection{Técnica de Correção Fuzzy}

A Lógica Fuzzy é de simples implementação desde que se conheça o comportamento do sistema. No caso deste trabalho, são os perfis de carga medidos pelo Sistema SCADA nas subestações.

O primeiro passo consiste na separação do banco de dados anual nos sete dias da semana. Logo em seguida, foram calculados os valores máximo e mínimo de cada dia para a normalização entre 0 e 1 :

$$
P^{\prime}[n]=\frac{P[n]-\min [P]}{\max [P]-\min [P]}
$$

com $P^{\prime}[n]$ representando o valor normalizado da potência, $P[n]$ sendo o valor medido de entrada, $\max [P]$ e $\min [P]$ sendo as funções que retornam os valores máximo e mínimo daquele dia da semana da amostra em estudo. Por exemplo, se o dia tratado for uma Quarta-feira, então serão considerados os valores máximo e mínimo respectivos, que foram separados no primeiro passo. Após a normalização, são calculados os incrementos diferenciais que serão as entradas do bloco fuzzy (Figura 6):

$$
\begin{gathered}
d_{1}=P^{\prime}[n-1]-P^{\prime}[n-2] \\
d_{2}=P^{\prime}[n]-P^{\prime}[n-1]
\end{gathered}
$$

em que $P^{\prime}[n-1]$ é o valor normalizado da medição imediatamente anterior, $P^{\prime}[n-2]$ é o valor que precede o valor anterior e $P^{\prime}[n]$ é o valor medição atual. 


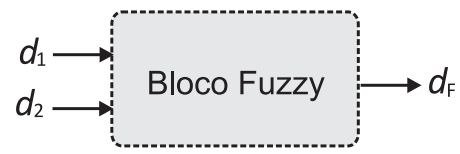

Figura 6: Modelo do bloco fuzzy com as entradas e saída referentes aos incrementos diferenciais.

O comportamento diário da carga foi modelado em 25 regras fuzzy ( 5 conjuntos de $d_{1} \times 5$ conjuntos de $d_{2}$ ) e a partir das magnitudes e dos sinais dos incrementos $\left(d_{1}\right.$ e $\left.d_{2}\right)$ foi determinada a saída do bloco $\left(d_{F}\right)$ que também é um valor incremental e será somado ao valor de $P^{\prime}[n]$ para determinar o valor estimado:

$$
P^{\prime}[n+1]=P^{\prime}[n]+d_{F}
$$

Portanto, a cada novo valor medido, o algoritmo identifica qual é o dia da semana, normaliza o valor de entrada de acordo com o máximo e o mínimo respectivos, e calcula os incrementos diferenciais para entrada no bloco fuzzy. O incremento diferencial de saída $\left(d_{F}\right)$ é adicionado ao valor medido, $P^{\prime}[n]$, resultando no valor estimado, $P^{\prime}[n+1]$. E, por fim, é aplicada a função inversa da Eq. 1. Desta forma, se na próxima iteração ocorrer um valor atípico, a medição será substituída por esse valor calculado.

\subsection{Técnica de Correção RNA}

A Técnica de Correção RNA é relevante por responder significativamente ao comportamento nãolinear das curvas de potência e, assim como a técnica Fuzzy, necessita de pouco conhecimento matemático-estatístico sobre o sistema. E, diferentemente da correção fuzzy, não é preciso conhecer de forma profunda o comportamento dos perfis de carga.

Antes da aplicação da técnica sobre as curvas de carga foram necessários dois procedimentos: o tratamento dos dados e o treinamento da rede.

Foram selecionados aleatoriamente 21 dias do histórico de um ano com 3 representantes de cada dia da semana, isto é, 3 domingos, 3 segundas, e assim por diante. Estes dados foram utilizados para a composição das matrizes de entrada e de alvo da rede neural. A janela de amostras anteriores utilizada foi igual a 10 medições, ou seja, as entradas da rede são 10 medições válidas e a saída é o valor previsto, como ilustrado na Figura 7. Foi feito o "deslizamento"da janela sobre o banco de dados para composição das matrizes de entrada e de alvo que foram usadas no processo de treinamento.

\subsection{Técnica de Correção Híbrida}

Foi observado após diversos estudos sobre as curvas de potência e sobre as técnicas de correção utilizadas quais eram os intervalos do dia em que as

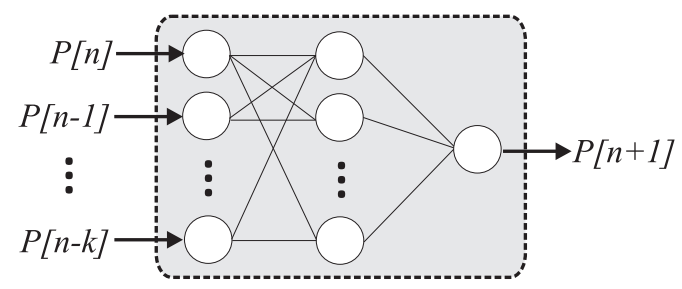

Figura 7: Rede Neural para estimação do próximo valor. A janela utilizada foi de 10 amostras $(\mathrm{k}=9)$.

Tabela 1: Faixas de Intervalos e Técnica de melhor desempenho.

\begin{tabular}{|c|c|c|c|}
\hline Faixa 1 & Faixa 2 & Faixa 3 & Faixa 4 \\
\hline Fuzzy & RNA & Fuzzy & RNA \\
\hline $1: 20$ & $21: 40$ & $41: 64$ & $65: 96$ \\
\hline
\end{tabular}

técnicas Fuzzy e RNA se sobressaíam melhor. A Técnica de Correção Fuzzy tem um melhor desempenho nas regiões mais constantes do dia com os índices pertencendo ao intervalo [1:20] e [41:64]. E quando há uma maior mudança na magnitude e no sinal da derivada dos pontos da curva, isto é, nos pontos de maior variação de carga, a Técnica de Correção RNA tem uma maior performance por responder melhor ao comportamento não-linear das curvas. O intervalo de melhor desempenho da Técnica RNA é [21:40] e [65:96], como ilustrado na Tabela 1 e Figura 8.

É importante observar que o melhor desempenho em cada faixa não é exclusivo e generalizado daquela técnica respectiva. Apesar dos perfis de carga possuírem um padrão que se repete ao longo dos anos, muitas vezes ocorrem variações pontuais na demanda que mudam o comportamento da curva e pode ocorrer da Técnica $R N A$ se sobressair melhor na faixa Fuzzy. Por exemplo, se na região do intervalo [41 : 64], em que a Técnica Fuzzy é melhor, houver uma elevação abrupta de potência ocasionada por um aumento na carga, então a Técnica RNA responderá melhor por ter desempenho superior quando há grandes variações. Ainda assim, neste caso, a Técnica Híbrida irá utilizar a lógica fuzzy, pois o intervalo de aplicação de cada técnica é fixo. Portanto, nestes casos pontuais, a Técnica Híbrida terá um desempenho inferior. Por fim, é importante ressaltar que, para essa subestação, a carga se comporta de maneira regular ao longo do tempo, favorecendo a aplicação da Técnica Híbrida desenvolvida.

\section{Resultados e Discussões}

Os resultados serão divididos em duas abordagens: a primeira terá o período de 1 dia e será detalhada a vantagem do algoritmo híbrido sobre as duas outras técnicas comparadas. A segunda testará a robustez das técnicas para um intervalo de 6 anos. O banco de dados foi coletado de uma subestação 


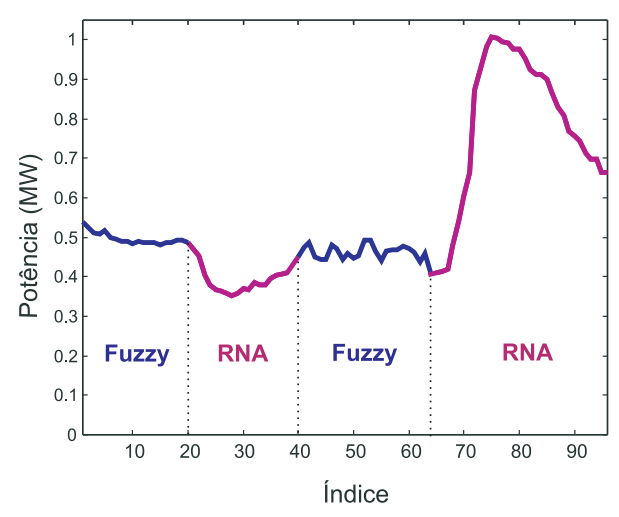

Figura 8: Intervalos fixos para aplicação das Técnicas de Correção Fuzzy e RNA.

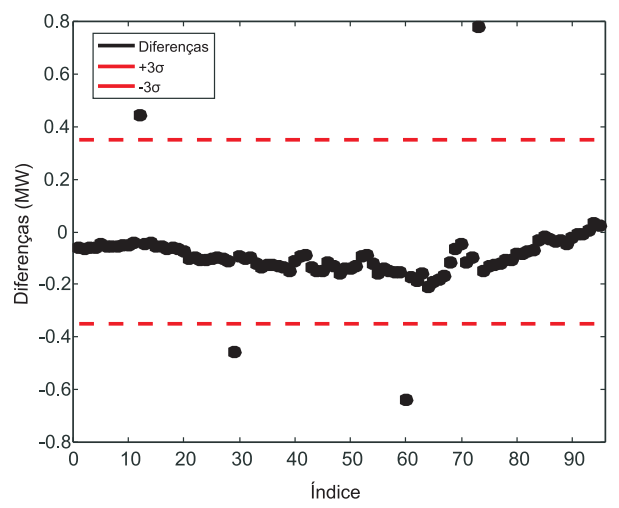

Figura 9: Gráfico das diferenças e limites associados ao triplo do desvio padrão máximo do respectivo dia da semana.

real localizada no município de Cuité, no estado da Paraíba, e corresponde às medições no tronco do quarto alimentador.

\subsection{Primeiro Cenário: 1 dia}

Para o primeiro cenário de teste, foram inseridos aleatoriamente 4 outliers (dois vales e dois picos) sobre a curva de um dia do alimentador estudado. A detecção é ilustrada na Figura 9 em que as diferenças dos valores medidos e o valor típico respectivo encontram-se fora da região de medições

Tabela 2: Erros relativos para cada técnica de correção no período de 1 dia.

\begin{tabular}{|c|c|c|c|}
\hline Índice & $\begin{array}{c}\text { Erro R. } \\
\text { Fuzzy } \\
\mathbf{( \% )}\end{array}$ & $\begin{array}{c}\text { Erro R. } \\
\text { RNA } \\
(\mathbf{\%})\end{array}$ & $\begin{array}{c}\text { Erro R. } \\
\text { Híbrido } \\
\mathbf{( \% )}\end{array}$ \\
\hline 12 & 0,26 & 1,72 & 0,26 \\
\hline 29 & 4,89 & 0,85 & 0,85 \\
\hline 60 & 0,93 & 3,82 & 0,93 \\
\hline 73 & 6,08 & 0,79 & 0,79 \\
\hline $\begin{array}{c}\text { Média } \\
\text { Erro (\%) }\end{array}$ & $\mathbf{3 , 0 4}$ & $\mathbf{1 , 8 0}$ & $\mathbf{0 , 7 1}$ \\
\hline
\end{tabular}

Tabela 3: Erros relativos para cada técnica de correção no período de 6 anos.

\begin{tabular}{|c|c|c|c|}
\hline Técnica & $\begin{array}{c}\text { Fuzzy } \\
(\boldsymbol{\%})\end{array}$ & $\begin{array}{c}\text { RNA } \\
(\boldsymbol{\%})\end{array}$ & $\begin{array}{c}\text { Híbrida } \\
(\mathbf{\%})\end{array}$ \\
\hline $\begin{array}{c}\text { Média } \\
\text { Erro (\%) }\end{array}$ & 4,84 & 4,64 & 4,37 \\
\hline
\end{tabular}

válidas, identificando os outliers simulados. Após a detecção, é feita a previsão utilizando as técnicas implementadas e o resultado gerado por cada técnica é comparado com o valor real conhecido, a partir do cálculo dos erros relativos.

A Tabela 2 indica a média dos erros relativos de cada uma das técnicas desenvolvidas. Nesta tabela pode-se observar que ocorreu um outlier em cada uma das faixas de intervalo. Para a primeira faixa, em que a Técnica Fuzzy tem uma melhor performance, o erro relativo médio desta técnica foi menor que o da Técnica RNA, sendo então igual ao erro da abordagem híbrida. A mesma análise ocorre para as outras três faixas em que os menores erros relativos médio são das Técnicas RNA, Fuzzy e RNA, respectivamente. O que a abordagem híbrida faz é aproveitar a melhor performance (menor erro) de cada técnica, portanto o desempenho é significativamente superior. Neste caso, a média do erro relativo híbrido é $0,71 \%$, equivalente a menos da metade da média do erro relativo da técnica RNA que apresentou 1,80\% e ainda mais inferior a média do Fuzzy com 3,04\%.

\subsection{Segundo Cenário: 6 anos}

Para o segundo cenário de testes, foram inseridos também de forma aleatória 10\% do total de 210432 medições como sendo outliers: $8 \%$ do tipo vale e $2 \%$ do tipo pico. As medições errôneas simuladas também foram sobre o alimentador 21L4.

A média dos erros relativos são indicados na Tabela 3 e mais uma vez a abordagem híbrida obteve a melhor performance com a média do erro relativo igual a $4,37 \%$. Diferentemente do cenário anterior, a diferença para a média do erro da Técnica RNA foi um pouco menor, pois muitos casos são considerados como os pontos em que a suposta técnica de melhor performance não corresponde e apresenta desempenho inferior.

A Figura 10 ilustra as curvas no período de 6 anos com os valores simulados em vermelho e os dados corrigidos pela técnica híbrida são destacados na cor preta.

Outra vantagem da aplicação do módulo de tratamento de outliers proposto é a supervisão da qualidade e integralidade das medições. É comum na concessionária não haver um acompanhamento das medições e quando se necessita dos dados para os estudos internos, o histórico está comprometido com muitas medições errôneas. Nas análises para desenvolvimento deste trabalho, foram estudados 


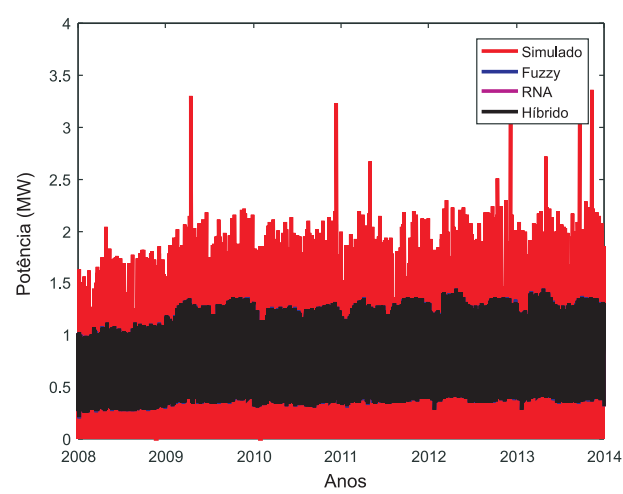

Figura 10: Curvas do período de 6 anos com os valores simulados e com os dados corrigidos pela abordagem híbrida.

perfis de carga de subestações com meses de dados ausentes, inviabilizando qualquer tipo de análise por parte da distribuidora.

O módulo proposto indica através de uma flag de sinalização que as medições que estão sendo adicionadas ao banco de dados não são adquiridas pelo sistema de medição, além disso também é feita a indicação do número de amostras que foram geradas pelo algoritmo de tratamento de outliers. Com o conhecimento dos sistemas de medições que estão defeituosos, a concessionária poderá gerar um plano para correção dos problemas expostos pelo método proposto.

\section{Conclusão}

O módulo de tratamento de outliers nas curvas de potência agregado ao Sistema SCADA garante uma maior confiabilidade nos dados medidos nas subestações. O banco de dados gerado é utilizado para análises internas e previsões de demanda a médio e longo prazo pelas distribuidoras, portanto a integralidade e a qualidade são indispensáveis nesses estudos.

Neste trabalho foram implementadas uma técnica de detecção de outliers e três técnicas de correção de outliers que foram comparadas entre si: RNA, Fuzzy e Híbrida, sendo esta última a de melhor performance por utilizar as técnicas anteriores em faixas predeterminadas e que apresentou média do erro relativo igual a $4,37 \%$ para o cenário que considera 6 anos de dados, sendo a nova técnica proposta a de melhor desempenho.

As técnicas de detecção e correção utilizadas são simples e não exigem um esforço computacional elevado, podendo ser utilizadas agregadas ao Sistema SCADA para melhorar a qualidade dos sistemas de medição das subestações de distribuição.

\section{Referências}

Andrade, P. H. M., Villanueva, J. M. M. and Braz, H. D. M. (2018). Detecção e correção automática de outliers para sistemas supervisóriose subestações. Congresso Brasileiro de Automática (CBA).

Charytoniuk, W. and Chen, M. (2000). Very short-term load forecasting using artificial neural networks. IEEE Trans. Power Systems, vol. 15, pp. 263-268.

Fang, X., Misra, S., Xue, G. and Yang, D. (2012). Smart grid-the new and improved power grid: A survey. IEEE Commun. Surv. Tuts., vol. 14, no. 4, pp. 944-980.

Lanzrath, M., Adami, C., Joerres, B., Lubkowski, G., Joester, M., Suhrke, M. and Pusch, T. (2017). Hpem vulnerability of smart grid substations coupling paths into typical scada devices. Proc. of the 2017 International Symposium on Electromagnetic Compatibility.

Melo, D. C. R. and Castro, A. R. G. (2014). Uma nova abordagem para detecção e correção de outliers em séries temporais: Aplicação em consumo de energia elétrica. Simpósio Brasileiro de Sistemas Elétricos SBSE.

Valverde, G. and Terzija., V. (2011). Unscented kalman filter for power system dynamic state estimation. Generation, Transmission and Distribution, IET, vol. 5, no. 1, pp. 29-37.

Xenias, D., Axon, C. J., Whitmarsh, L., Connor, P. M., Balta-Ozkan, N. and Spence, A. (2015). Uk smart grid development: An expert assessment of the benefits, pitfalls and functions. In Renewable Energy, Volume 81, pp. 89-102.

Yang, Q., Yang, J., Yu, W. and Zhang, N. (2011). On a hierarchical false data injection attack on power system state estimation. Global Telecommunications Conference (GLOBECOM 2011), pp. 1-5.

Ye, X., Lu, Z., Qiao, Y., Min, Y. and O’Malley, M. (2016). Identification and correction of outliers in wind farm time series power data. IEEE Transactions on Power Systems, vol. 31, pp. 4197-4205.

Zhang, J., Welch, G., Bishop, G. and Huang, Z. (2011). A two-stage kalman filtering approach for robust and real-time power systems state tracking. IEEE Transactions on Sustainable Energy, vol. 5, no. 2, pp. 629-636. 